ESTUDIO

\title{
LAS INSTITUCIONES EN EL CRECIMIENTO ECONÓMICO*
}

\author{
Francisco Rosende
}

La relación entre el marco institucional y el desempeño económico de los países ha sido un tema que por muchos años ha concitado el interés de los economistas.

En la última década, la discusión y análisis de ese vínculo ha registrado un renovado ímpetu, pues se ha observado que hay países que logran sostener fuertes tasas de crecimiento del producto por habitante durante un período prolongado - especialmente atractivo ha sido el caso de los denominados "tigres del sudeste asiático"mientras en otros persiste un cuadro de subdesarrollo y de recurrentes desequilibrios macroeconómicos. Dentro del análisis de estas disímiles experiencias, una vertiente de la investigación ha destacado la importancia de la estructura institucional de un país en la marcha de su economía.

Esta agenda de investigación, que tuvo una fuerte influencia en la “economía clásica”, ha resurgido con fuerza gracias a las contribucio-

Francisco Rosende R. Decano de la Facultad de Ciencias Económicas y Administrativas, P. Universidad Católica de Chile. Investigador asociado del Centro de Estudios Públicos.

* Una versión preliminar de este trabajo se presentó en el Seminario "Perspectivas para el Crecimiento Económico en Chile: Incertidumbres y Certezas”, organizado por la Vicerrectoría de Comunicaciones y Asuntos Públicos de la P. Universidad Católica de Chile. Agradezco los valiosos comentarios de Francisco Gallego, Edgardo Jürgensen, Diego Saravia y Gert Wagner, así como las observaciones recibidas de Juan Claro y Andrés Solimano en dicho seminario.

Estudios Públicos, 111 (invierno 2008). 
nes realizadas por el Premio Nobel de Economía Douglas North, y más recientemente por el economista del MIT, Daron Acemoglu.

El presente trabajo expone los fundamentos conceptuales de esta línea de investigación, para posteriormente advertir los desafíos y problemas que enfrenta. En particular, se ilustra la influencia de las variables institucionales en el desempeño macroeconómico con algunas de las reformas realizadas en Chile a partir de mediados de los años setenta.

\section{Introducción}

ت

la última década ha adquirido popularidad entre los economistas la hipótesis de que la estructura institucional de un país es un determinante de importancia de la tasa de crecimiento que éste registre, como también del comportamiento de otros indicadores macroeconómicos, como la inflación. Desde esta perspectiva, el análisis del conjunto de "reglas del juego" que configuran el entorno en el cual se desarrolla la actividad productiva es un aspecto esencial para comprender las diferencias que se observan en el desempeño de las diferentes economías.

Esta línea de investigación retoma algunos rasgos característicos del estudio de la economía desarrollado por Adam Smith, Karl Marx, John Stuart Mill y otros economistas "clásicos", en tanto se inserta en una perspectiva más amplia que la habitualmente usada en esta disciplina, pues también considera la influencia de factores políticos, sociales y/o culturales. En la investigación reciente, el énfasis en los factores institucionales como causa del crecimiento de largo plazo de las economías se encuentra estrechamente vinculado con los trabajos que ha liderado el Premio Nobel de Economía 1993 Douglas North, y más recientemente el economista del MIT ${ }^{1}$ Daron Acemoglu.

En esta agenda de investigación ocupa un lugar preponderante el estudio de los procesos que llevan a alterar el conjunto de reglas dentro de las cuales se inserta la actividad productiva y la forma en que se distribuyen las utilidades y pérdidas resultantes. Ello requiere identificar la influencia política de los diferentes grupos de la comunidad y la mecánica mediante la cual ésta evoluciona, para desde allí examinar episodios en los que se observó un cambio importante en el marco económico de un país y, como consecuencia de ello, en la tasa de crecimiento del producto, la inflación o el

${ }^{1}$ Massachusetts Institute of Technology. 
manejo de las finanzas públicas. Este enfoque no sólo se ha utilizado para el estudio de problemas macro, sino también de orden microeconómico, como sería el análisis del marco institucional en el que se desenvuelve el mercado laboral, o algún sector específico como el educacional.

Definir con precisión lo que se entiende por el "marco institucional" de una economía no es trivial. En general este concepto se asocia con la forma en que se relacionan los poderes públicos de un país, las restricciones que enfrenta la autoridad en el ejercicio de sus funciones, como también con el grado de protección que tienen la propiedad privada y los contratos entre individuos. Así, aspectos tales como el grado de representación de las diferentes provincias en el Parlamento, el grado de independencia del Poder Judicial y el grado de centralización de las decisiones de políticas públicas debieran de algún modo estar incluidos dentro de una agenda de investigación que destaque la influencia de la estructura institucional de un país en el desempeño económico del mismo.

Una definición para el concepto de "marco institucional” corresponde a la propuesta por North (1990), quien asoció la estructura institucional con "las reglas del juego" conforme a las cuales se desenvuelve la actividad económica:

Las instituciones son las reglas del juego que existen en una sociedad, o más formalmente, son las restricciones ideadas por los hombres para moldear las interacciones humanas².

Sin embargo, con anterioridad el propio North había propuesto una definición para "el marco institucional" que — sin contradecir la expuesta más tarde- pone el acento en el conjunto de restricciones que se configuran en una sociedad sobre el proceder de sus actores. Como es lógico, esta perspectiva lleva a subrayar las consecuencias de aquellas restricciones que enfrentan los diferentes poderes públicos de un país:

un conjunto de reglas, procedimientos y de normas de conducta - morales y éticas - concebidas para restringir la conducta de los individuos en aras de maximizar la riqueza o el bienestar social ${ }^{3}$.

Como veremos más adelante, el énfasis que pone cada definición plantea ciertas dificultades prácticas al momento de evaluar el marco institucional de un país. En términos generales, este conflicto aparece en los casos

\footnotetext{
${ }^{2}$ North (1990), p. 3. Traducción propia.

${ }^{3}$ North (1981), p. 201. Traducción propia.
} 
— relativamente habituales - de países en los que no existía un sistema democrático desarrollado, o simplemente prevalecía algún tipo de dictadura, pero donde ésta dio forma a un conjunto de reglas "amistosas" con el desarrollo de la actividad productiva, las que posteriormente impulsaron el crecimiento de la economía en cuestión. Parece claro que la definición que enfatiza la "estabilidad de las reglas" no conduce a la misma evaluación del marco institucional que aquella definición que subraya las "restricciones" formales que enfrenta la autoridad.

El problema es complejo. Con todo, pareciera que la experiencia de países que iniciaron un amplio proceso de reformas económicas (cambio en las reglas del juego) que les permitió dar un fuerte impulso al crecimiento, sin que ocurrieran cambios importantes en la organización política —como sucedió en varias de las exitosas economías asiáticas-, ha dado un mayor peso al enfoque que enfatiza esta variable (reglas del juego). En la discusión misma de la interacción entre crecimiento e institucionalidad retornaremos sobre este punto.

El propósito de este artículo es describir los aspectos esenciales de este enfoque que destaca la importancia del marco institucional en el crecimiento, dando cuenta de las controversias que ha generado. Sin embargo, la idea no es realizar una revisión de la literatura, sino que establecer los rangos centrales del debate y, desde ahí, examinar las implicancias de este enfoque a partir de la realidad observada en las economías latinoamericanas y especialmente en la chilena.

Aun cuando la literatura y la discusión pública relacionadas con el proceso de crecimiento económico se continúan planteando en términos del proceso de acumulación de factores productivos y de tecnología, este enfoque "institucional" permite poner de relieve ciertos aspectos que subyacen en el diseño de política económica. Sin embargo, parece aventurado suponer que éste constituye un camino alternativo o contradictorio con el que ha predominado en la profesión por varias décadas.

\section{Las instituciones como fuente del crecimiento económico}

En un trabajo publicado en el año 2003, Acemoglu y Johnson analizan la relación entre los derechos de propiedad (property rights institutions), el marco que regula el diseño de contratos entre los privados (contracting institutions) y la tasa de crecimiento de largo plazo de un conjunto de economías. Encuentran que los derechos de propiedad —que cautelan del riesgo de expropiación — tienen efectos de primer orden sobre la tasa de crecimiento de 
una economía, mientras que las reglas que definen la naturaleza de los contratos sólo inciden sobre las características del proceso de intermediación financiera. A mi juicio, este resultado se explica por el hecho de que los individuos pueden, en general, diseñar mecanismos de contratación y recontratación en forma descentralizada. Sin embargo, no existen arreglos privados que puedan resolver el problema que plantea un riesgo de expropiación.

Si bien el análisis de los derechos de propiedad se plantea en torno a lo que ocurre con un índice de expropiación, pareciera razonable suponer que esta línea de argumentación es coherente con una perspectiva más amplia del problema, la que incluye ajustes en las tasas de impuestos que establecen las autoridades correspondientes. Ello por cuanto para quienes llevan a cabo decisiones de inversión, los cambios en la política tributaria pueden representar una forma diferente — pero más relevante en la práctica- de expropiación de su riqueza. Así, por ejemplo, algunos trabajos ${ }^{4}$ han advertido respecto a este tipo de prácticas expropiatorias en economías con un bajo grado de desarrollo, donde existe una alta tasa de pobreza. En este escenario es frecuente encontrar que la ejecución de políticas redistributivas toma la forma de altas tasas de impuestos sobre las utilidades de las empresas y/o el ingreso de las personas, lo que restringe la inversión y mantiene a dicha economía en una "trampa de pobreza". En este caso, si bien se corrobora el diagnóstico que subraya la importancia de los factores institucionales en la configuración del problema planteado, se hace una interpretación más amplia de lo que Acemoglu y Johnson (2003) denominan como "property rights institutions", la que habría que contrastar empíricamente con la utilizada en el estudio.

Más tarde, Acemoglu, Johnson y Robinson ${ }^{5}$ (AJR) elaboran un planteamiento más general y extenso respecto del vínculo entre crecimiento e institucionalidad. Para ellos, ésta es la perspectiva de análisis adecuada para comprender las fuerzas que impulsan el progreso de las economías y las diferencias que se observan entre éstas. Así, sostienen que plantear el debate entre las diferentes teorías del crecimiento en términos del énfasis que éstas ponen en la inversión en capital físico versus aquellas que destacan la inversión en tecnología o en capital humano, es poco útil conceptualmente, por cuanto la evolución de los diferentes factores propuestos como determinantes del crecimiento dependería de las características del entorno institucional vigente. En otras palabras, la evolución del capital humano, de la tasa de innovación en tecnología o de la formación de capital físico serían el resultado del andamiaje institucional existente, lo que haría poco razona-

\footnotetext{
${ }^{4}$ Una discusión general de este tema se encuentra en Barro (1999a).

${ }^{5}$ Acemoglu, Johnson y Robinson (2004).
} 
ble estructurar una teoría a partir del comportamiento de variables endógenas.

Las variables institucionales también han ocupado un lugar importante dentro del trabajo empírico dirigido a establecer las causas del crecimiento. Así por ejemplo, Barro (1997) encuentra que variables tales como un índice de democracia y un indicador de la fortaleza del "estado de derecho" 6 pueden explicar una fracción importante de las diferencias en las tasas de crecimiento del producto por habitante entre países. No obstante, esta línea de investigación no es coincidente con el "enfoque institucional" que actualmente lidera Acemoglu, por cuanto el marco de referencia utilizado en las investigaciones de Barro y Sala-i-Martin, por ejemplo, viene dado por el modelo neoclásico de crecimiento, el que enfatiza el protagonismo del proceso de acumulación de factores en la determinación del crecimiento. En este contexto, la introducción de variables institucionales en la investigación empírica se justifica por el propósito de caracterizar los determinantes del estado estacionario de una economía, respecto al cual se evaluará la “convergencia $\beta$ condicional” , más que como teoría del crecimiento propiamente tal.

En esta investigación empírica de los determinantes de la tasa de crecimiento del producto por habitante, Barro (1997) encuentra un efecto negativo de la inflación sobre el crecimiento, resultado que también podría ser examinado desde la perspectiva del marco institucional vigente. Ello, considerando la importancia que una vertiente de literatura le ha otorgado al esquema institucional en que se desenvuelve el banco central en la determinación del grado de estabilidad de precios que observe una economía. Por ejemplo, a través del grado de autonomía del banco central ${ }^{8}$ respecto al gobierno de turno y del peso político relativo de quienes pierden con la inflación con respecto al de aquellos sectores que se benefician de este proceso $^{9}$. Más aun, algunos estudios han encontrado que el grado de estabilidad política tendría una influencia apreciable en la inflación, puesto que en escenarios de alta conflictividad los partidos no estarían dispuestos a asumir los costos del ordenamiento de las finanzas públicas, por lo que se recurriría al financiamiento monetario del gasto fiscal ${ }^{10}$. Desde esta perspectiva, la inflación reflejaría un cuadro de crisis institucional, el que en alguna medida repercutirá sobre la tasa de crecimiento del país.

\footnotetext{
${ }^{6}$ En inglés, the rule of law.

${ }^{7} \mathrm{Al}$ respecto véase Barro y Sala-i-Martín (2004).

${ }^{8} \mathrm{Al}$ respecto, véase Cukierman, Webb y Neyapti (1993).

${ }^{9}$ Posen (1993).

${ }^{10}$ Cukierman, Edwards y Tabellini (1992).
} 
Un razonamiento similar lleva a examinar el papel de las instituciones en el comportamiento de variables como la deuda pública y el gasto de gobierno ${ }^{11}$, las que, de acuerdo a los resultados empíricos obtenidos por Barro, serían importantes para explicar el crecimiento de una economía a lo largo del tiempo. En lo que se refiere a la dinámica de las finanzas públicas, se plantea que la trayectoria que sigan el gasto público y el nivel y composición de los impuestos dependerá crucialmente del peso político de quienes serán potenciales beneficiados con dicho gasto, con relación al peso de quienes serán gravados para financiarlos. Como es evidente, dicha dinámica no es neutral al dinamismo que registre la economía ${ }^{12}$.

El papel de la estructura institucional también está presente en aquellas teorías del crecimiento que subrayan la importancia de las innovaciones tecnológicas como una fuente de este proceso ${ }^{13}$. Ello por cuanto el desarrollo de nuevos conocimientos y tecnologías no sólo exige un marco institucional respetuoso del derecho de propiedad, sino que, además, que no castigue las utilidades que genera de la innovación, aun cuando éstas pudieran adquirir temporalmente el carácter de monopólicas.

En esta perspectiva, la forma en que el marco institucional logre armonizar el establecimiento de mercados competitivos con una estructura de incentivos amistosa con la innovación — aun cuando ésta pudiese originar posiciones monopólicas por algún tiempo- será un elemento importante en la determinación de las tasas de crecimiento de una economía. Al menos de aquellas que han superado la etapa del crecimiento basada en la búsqueda de una asignación de los recursos productivos y que sustentan este proceso en la innovación en tecnología.

\section{La dinámica de la teoría institucional}

Para Acemoglu et al. (2004), los dos variables centrales ${ }^{14}$ para el estudio del proceso de crecimiento son:

— las instituciones políticas

— la distribución de los recursos en la sociedad.

La primera variable determinaría el poder político formal (de jure) en la sociedad, mientras que la segunda determinaría el poder de hecho (de facto).

\footnotetext{
${ }^{11}$ Ambas como porcentaje del PIB.

${ }^{12} \mathrm{Al}$ respecto véase Barro (1999b).

13 Romer (1992).

${ }^{14}$ Variables "estado", en la terminología de los problemas de control óptimo dentro de los que se inscribe el crecimiento económico.
} 
Es importante señalar que la idea que se expresa a través de la “distribución de recursos” no se limita a la distribución del ingreso en la sociedad, sino que también incorpora otras fuentes de recursos que podrían ser utilizadas en un momento para influir en la definición de las "reglas del juego” de la sociedad. En esta categoría se incluye — por ejemplo- el liderazgo que puede alcanzar un dirigente sindical, como fue Lech Walesa en Polonia a mediados de los 80.

La interacción entre las instituciones y el crecimiento - o el desempeño económico en general- la describen Acemoglu et al. (2004) a través del Diagrama $N^{\circ} 1$ :

DIAGRAMA N 1

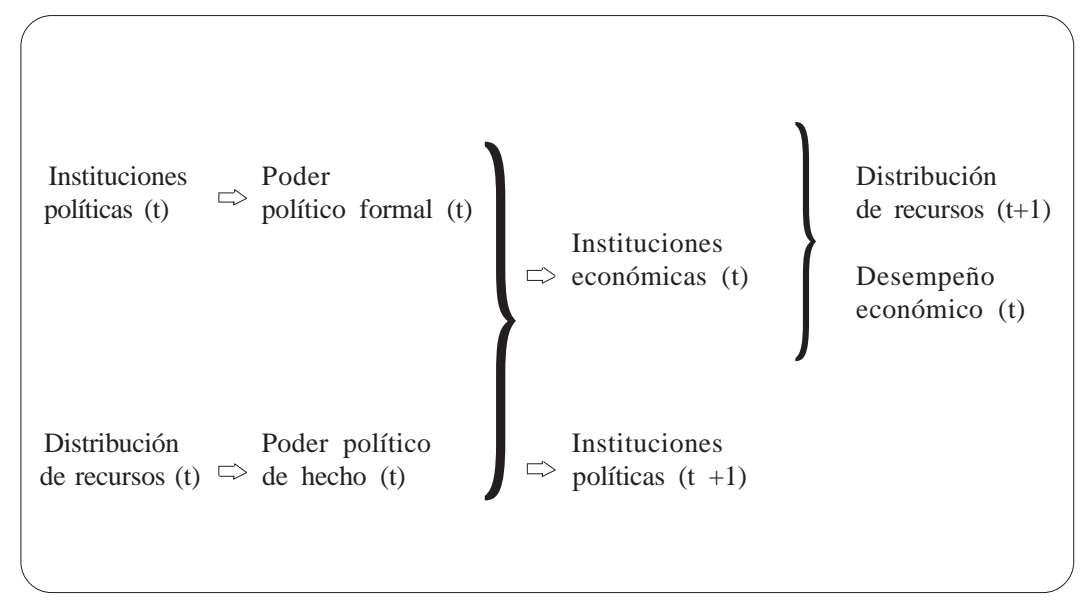

De acuerdo con la lógica que plantea el diagrama, las instituciones económicas determinan el desempeño de la economía de un país, pero a la vez ellas son determinadas por el "peso político" de los diversos sectores de la sociedad, reflejando el hecho de que la organización económica no es neutral en cuanto a sus efectos distributivos.

Como se indica en el diagrama, los cambios que eventos exógenos provoquen sobre la distribución de fuerzas políticas de una sociedad pueden acarrear consecuencias importantes sobre el desempeño de la economía y de allí en la distribución de recursos de los períodos siguientes. En esta perspectiva, parece razonable suponer que una recesión severa —ya sea que se origine en errores de la política económica o en factores ajenos a ésta- podría promover una redistribución de recursos y/o de poder políti- 
co que termine modificando la estrategia de política económica, el desempeño global de la economía e incluso las "reglas de juego" económico ${ }^{15}$.

En los diferentes casos analizados por Acemoglu et al. (2004) se identifican aquellos factores que influyeron en el diseño institucional y a través de ello en el crecimiento. Así por ejemplo, destacan la importancia del contrapeso a la monarquía que representó el poder alcanzado por los comerciantes en la Inglaterra de mediados del siglo XVII, lo que habría sido determinante en la configuración de una estructura institucional coherente con el desarrollo de la propiedad y la iniciativa privada. En este caso, el desarrollo de un intenso comercio con el exterior otorgó importantes recursos y con ello poder de facto a un grupo importante de empresarios y navegantes.

En sus investigaciones, Acemoglu et al. también subrayan la diferente "inversión en instituciones" realizada por los conquistadores europeos en las colonias. Para ellos, los colonizadores invirtieron más en el desarrollo institucional de aquellos lugares en los que visualizaron la perspectiva de asentarse, lo que habría determinado el posterior desarrollo de dichas colonias. Señalan, además, que un determinante de importancia en la decisión respecto a cuánto "invertir" en las instituciones de una colonia fue el grado de concentración urbana prevaleciente en ella, puesto que dicha variable incidía en la posibilidad de que los colonizadores pudiesen imponer sus reglas y cultura a los “locales". Así, en aquellos poblados de mayor densidad, donde la posibilidad de lograr dicho objetivo era más baja, no habría habido gran interés por comprometerse en su desarrollo institucional.

A su vez, Acemoglu et al. (2004) destacan cómo la cuantía de las riquezas extraíbles en un corto plazo incidió en la estrategia adoptada por los "conquistadores" en cuanto al esfuerzo que dedicarían al diseño institucional de cada una de las colonias. De este modo, cuando las riquezas eran importantes y podían ser obtenidas rápidamente, el colonizador no se preocupó mayormente de invertir en el diseño de un marco institucional de largo plazo, sino que se definieron reglas coherentes con la rápida extracción y embarco de dichos recursos.

El vínculo que establecen Acemoglu et al. (2004) entre el diseño institucional de las colonias ${ }^{16}$, su posterior crecimiento y las motivaciones del "conquistador" parece debatible en varios aspectos, sin embargo, éste

${ }^{15}$ En este caso no se podría sostener que la tendencia de crecimiento es independiente de las fluctuaciones en torno a ésta, como se supone en la teoría tradicional del ciclo económico.

${ }^{16}$ Respecto a este tema también véase Bruhn y Gallego (2006). 
tiene el mérito de poner de relieve la influencia del marco institucional en el desempeño de las economías.

Una somera inspección de la historia económica de Latinoamérica permite levantar algunas dudas y cuestionamientos a la hipótesis planteada. Por ejemplo, llama la atención el hecho de que países como Argentina y Chile, cuyo desempeño económico fue inicialmente exitoso, lo que en el contexto mencionado cabría atribuir al aporte del marco institucional que surgió de los “colonizadores”, más tarde entraran en una declinación pronunciada en términos de su dinamismo. En esta perspectiva, parece razonable preguntarse cómo y por qué los países destruyen —en algún gradouna institucionalidad exitosa. Si bien es posible aventurar alguna explicación a partir del diagrama antes expuesto, parece necesario un tratamiento riguroso de dichos procesos, tanto en términos de lograr una mayor riqueza del análisis como de sustentar acciones que permitan actuar en la dirección opuesta. Esto es, de revitalizar el proceso de crecimiento en el tiempo.

Respecto al caso de Argentina, es interesante considerar que hasta inicios del siglo pasado exhibía un producto por habitante superior $-\mathrm{O}$ al menos similar - al de sus "conquistadores” y también al de países donde aparentemente el conquistador había invertido más en desarrollo institucional, como se puede apreciar en el Cuadro $N^{\circ} 1$. Sin embargo, de pronto este país entró en un proceso de lento crecimiento, que lo llevó a declinar sostenidamente en los rankings de progreso.

Algo parecido se observa en el caso de Chile, país que también registra un satisfactorio desempeño económico hasta la irrupción de la crisis del salitre, para luego de la Gran Depresión emerger con un bajo dinamismo, el que se hizo especialmente evidente a partir de la década del 60, dado el fuerte dinamismo que experimentó la economía mundial en el período de posguerra.

¿Fue la redistribución de riqueza y de poder político que provocó la Gran Depresión la causa de cambios institucionales que frenaron el crecimiento? Pareciera que en buena medida ello fue así, puesto que la severidad de la crisis provocada por dicho episodio promovió una tendencia mundial a responsabilizar al libre mercado del mismo, en el marco de "la revolución keynesiana”. Cuando la economía mundial recuperó un fuerte dinamismo - tras la Segunda Guerra Mundial— en el contexto de un fuerte incremento del comercio mundial, las economías latinoamericanas no participaron de dicho proceso al mantenerse apegadas a un esquema económico caracterizado por el enclaustramiento y una fuerte presencia del gobierno en la economía. 
CUADRO Nº 1: $\quad$ PIB PER CÁPITA (1990 dólares International Geary-Khamis)

\begin{tabular}{lrrr}
\hline & 1900 & 1965 & 2001 \\
\hline Argentina & 2.756 & 6.371 & 8.137 \\
Chile & 2.071 & 4.518 & 10.379 \\
& & & \\
Alemania & 2.985 & 9.186 & 18.677 \\
Francia & 2.876 & 9.361 & 21.092 \\
& & & \\
EE.UU. & 4.025 & 13.426 & 28.248 \\
Reino Unido & 4.492 & 9.752 & 20.127 \\
& & & \\
China & 545 & 706 & 3.583 \\
Japón & 1.180 & 5.934 & 20.683 \\
\hline
\end{tabular}

Fuentes: Díaz, Lüders y Wagner (2007); Maddison (2003), y OECD: The World Economy: Historical Statistics.

\section{Comentarios respecto al caso chileno en AJR (2004)}

Entre los ejemplos que plantean Acemoglu et al. (2004) para describir la forma en que las fuentes de poder descritas en el Diagrama $\mathrm{N}^{\mathrm{o}} 1$ inciden en el diseño institucional se incluye el golpe de Estado que tuvo lugar en Chile en 1973. Para ellos dicho episodio ilustra un caso en el que las Fuerzas Armadas utilizaron un poder político de facto para derribar a un gobierno democráticamente electo, que contaba con un poder político de jure.

Aun cuando el señalado episodio ha dado origen a diversas interpretaciones respecto a cuáles fueron sus causas y consecuencias, de la misma experiencia chilena es posible descubrir ilustraciones más precisas respecto al vínculo entre desarrollo institucional y resultados macroeconómicos. En efecto, es fácil identificar importantes transformaciones en el marco dentro del cual se insertó la política económica chilena a partir de mediados de los 70, las que podrían explicar los satisfactorios resultados que ésta obtuvo posteriormente. Así, la revisión del vínculo entre las transformaciones experimentadas por la economía chilena a partir del período mencionado y su posterior dinamismo constituye un atractivo caso de estudio. Esto parece coherente con la hipótesis que destaca la importancia de las "reglas del juego” en la determinación del desempeño económico de un país. En especial, de aquellas normas que limitan la capacidad de las autoridades para intervenir en la economía. 
El análisis de esta experiencia sólo se plantea desde una perspectiva conceptual. Se subrayan algunos cambios institucionales y, a partir de allí, se esbozan sus aparentes consecuencias. Luego, sólo se aspira a destacar la importancia de la dimensión institucional detrás de los resultados que observó la economía chilena en los últimos cuarenta años, más que a pretender que ésta sea la causa esencial o exclusiva de los mismos. Ello requeriría de un trabajo empírico que está pendiente.

Un antecedente esencial dentro del análisis de la experiencia macroeconómica chilena de los últimos cuarenta años es la caracterización del contexto en el cual se insertaba el diseño de políticas en el período. Así, una rápida revisión de los rasgos básicos de la estructura institucional existente a comienzos de los 70 lleva a concluir que ésta promovía la inestabilidad política y económica.

Cabe recordar que Salvador Allende fue elegido Presidente de la República el año 1970 con alrededor del 34\% de los votos. Si bien fue necesaria su ratificación por el Congreso, evidentemente ello no resolvió el hecho de que accedería al poder un candidato que sólo había alcanzado cerca de un tercio de los votos o, en su defecto, quien lo siguió en votación popular.

El programa de gobierno de Allende se proponía realizar transformaciones profundas en la sociedad chilena, por lo que desde el punto de vista de la estabilidad política hubiera sido deseable la existencia de algún mecanismo que promoviese acuerdos entre los partidos — formación de grandes coaliciones, por ejemplo_-, lo que en teoría al menos habría eliminado las reformas más radicales del candidato ganador.

En el plano económico, el marco institucional vigente hasta comienzos de los 70 favorecía la aparición de desequilibrios macroeconómicos y de distorsiones a nivel micro. En efecto, en dicho contexto el Parlamento tenía la posibilidad de impulsar iniciativas de gasto - actualmente ésta es atribución exclusiva del Poder Ejecutivo-, las que además podían atar a ciertas formas de financiamiento, como por ejemplo a un determinado impuesto. Como era de esperar, se generó una intensa dinámica de iniciativas de gasto público en el tiempo ${ }^{17}$, la que "inspiró" diferentes iniciativas de impuesto. Desde luego, esta estrategia terminó desperfilando cualquier intento de dar racionalidad al sistema tributario.

En dicho contexto, el Parlamento podía aprobar un presupuesto fiscal desfinanciado, lo que hacía necesario acudir al financiamiento moneta-

${ }^{17}$ Lo que por lo demás era coherente con una perspectiva socialista del sistema económico, la que se encontraba ampliamente extendida entre los diferentes grupos políticos. 
rio, con el consecuente efecto sobre la inflación. A lo anterior se añade que el Banco Central era dependiente del gobierno de turno, quien elegía a sus autoridades $^{18}$.

En la institucionalidad entonces vigente la autoridad monetaria contaba con amplios poderes para regular tanto el mercado del crédito como el mercado cambiario, lo que finalmente se tradujo en una compleja maraña de disposiciones. De acuerdo con éstas, las operaciones cambiarias realizadas fuera del régimen establecido por la autoridad podían adquirir el carácter de delitos penales y, por lo tanto, exponer a penas de cárcel a quienes participasen de ellas. Como era de esperar, los amplios poderes con que contaban las autoridades para establecer regulaciones y otorgar subsidios originaron importantes efectos distributivos, a los que cualquier cambio de sistema iba a afectar en algún grado.

Como resultado de la institucionalidad gruesamente expuesta, el país arrastró una inflación crónica ${ }^{19}$, en un contexto en el que la proliferación de distorsiones sobre el sistema de precios deterioró seriamente la capacidad de crecimiento, exacerbando las tensiones sociales y la aparición de propuestas de cambios radicales en la organización existente, lo que acentuó el conflicto político y la polarización.

Los cambios en la estructura institucional del país que se iniciaron con la Constitución de 1980 apuntaron a configurar un marco que impidiera la repetición de situaciones en las que un grupo político relativamente minoritario alcance el poder e implemente transformaciones profundas en la economía y la sociedad. Por otro lado, se establecieron ciertas normas conducentes a promover la disciplina fiscal, proceso que se inicia con las bases que establece la Ley de Administración Financiera del Estado de $1974^{20}$.

Como resultado del marco institucional que se construye para el manejo de las finanzas públicas, el Parlamento que inicia sus actividades en marzo de 1990 se encuentra con un escenario en el que: las decisiones de gasto están localizadas en el Ejecutivo y no en el Congreso; se elimina, o al menos limita, la asociación entre iniciativas de gastos fiscal y su financiamiento específico, lo que favorece el diseño de una estructura tributaria más eficiente; los ministerios no pueden tomar decisiones financieras — de endeudamiento, por ejemplo—-, proceso que se canaliza a través del Ministerio de Hacienda.

Por otro lado, del mismo proceso de reformas a la institucionalidad que impulsó la Constitución de 1980 surge la ley que consagra la autonomía

${ }^{18}$ En alguna etapa existió un directorio en el que se encontraban representados diferentes sectores productivos, junto con personeros del gobierno.

${ }^{19}$ Una discusión del comportamiento inflacionario en este período, dadas las necesidades de financiamiento fiscal, se plantea en Rosende (2008).

${ }^{20} \mathrm{Al}$ respecto véanse Méndez (ed.) (1979) y Larraín y Vergara (2000). 
del Banco Central, puesta en vigencia a fines de 1989. Ésta establece como objetivos de la autoridad monetaria la estabilidad de precios y en el sistema de pagos. Al mismo tiempo, se restringe a situaciones excepcionales $-\mathrm{y}$ por lo mismo transitorias - las atribuciones de la autoridad monetaria para establecer restricciones cambiarias, las que se habían desarrollado ampliamente en las décadas previas, como se indicó antes ${ }^{21}$.

Lo interesante del caso chileno es que, tras el cambio de gobierno de 1990, los diferentes gobiernos han mantenido los rasgos esenciales de la estructura institucional vigente, mientras han continuado con la inserción de la economía chilena al comercio internacional.

Si bien no es posible establecer de un modo riguroso cuál habría sido el resultado de la aplicación de la estrategia de política vigente en las últimas décadas en el marco institucional que prevaleció hasta 1973, parece razonable suponer que en dicho contexto se habría visto resentido el desempeño global de la economía, dada la propensión a generar desequilibrios y distorsiones que mostró el conjunto de "reglas del juego" vigentes hasta entonces.

Diferentes estudios empíricos, como el de Barro (1997), Barro (1999a) y el más reciente de Hernández y Parro (2008), destacan la importancia de los factores institucionales en el exitoso desempeño observado por la economía chilena a partir de mediados de los 80 , con relación al resto de las economías latinoamericanas. Para Hernández y Parro, alrededor de la mitad de la diferencia en desempeño se debe a diferencias en desarrollo institucional y la otra mitad a diferencias en las políticas seguidas. Pese al atractivo de esta línea de trabajo, que introduce en forma explícita indicadores de desarrollo institucional en el estudio del crecimiento, esta estrategia no permite establecer la interacción entre instituciones y políticas, las que, como se mencionó con respecto al diseño de las finanzas públicas y el de política monetaria, pueden ser parte importante de la explicación para un cuadro de mayor estabilidad.

\section{Instituciones en un "mundo plano"}

En el análisis de la forma en que una sociedad estructura sus instituciones, Acemoglu et al. (2004) introducen como concepto la "versión política del teorema de Coase”. De acuerdo con esta versión, aquellos grupos que bloquean la implementación de reformas favorables al agregado de la sociedad —al sentirse perjudicados por éstas—, en teoría al menos, podrían

${ }^{21} \mathrm{Al}$ respecto véase Fontaine (1989) y Rosende (1989). 
ser compensados de algún modo, lo que haría posible realizar los cambios necesarios para alcanzar un mejor desempeño de la economía. Sin embargo, Acemoglu et al. (2004) reconocen que este tipo de compensación habitualmente no se puede alcanzar, puesto que no existen mecanismos que lo posibiliten. En otras palabras, una vez que el grupo que se resiste a la modernización de las instituciones renuncia a su posición de poder para dar paso a un cambio político y a la implementación de reformas, parece difícil que pueda materializarse el mecanismo de compensación. Para ello se requeriría de un "tercer actor", el que habitualmente no existe entre la sociedad y ellos, que arbitre en este tipo de situaciones.

El problema es evidentemente complejo y explica por qué numerosos países que atraviesan por una situación de subdesarrollo severa no logran adecuar sus políticas e instituciones a un cuadro parecido al que observan aquellos que exhiben un desempeño exitoso. Así, para países como Corea del Norte o Cuba debiera ser bastante evidente que el modelo de desarrollo que han adoptado no es eficaz, lo que se ha traducido en un importante rezago de éstos con relación a otros que algunas décadas atrás tenían niveles parecidos de producto por habitante y que optaron por un camino opuesto. El problema entonces es: ¿cómo persuadir a los actuales dirigentes de dichos países para que abandonen el cargo y compensarlos por ello?

La ausencia de un mecanismo que permita llevar a cabo esta "transacción” tiende a mantener dictaduras como las mencionadas, o esquemas regulatarios ineficientes, como los que proliferaron en Europa occidental, en el contexto del welfare state.

Otra explicación posible para la mantención de estrategias de desarrollo ineficientes —aparte de la ausencia de esquemas de transacción entre las partes involucradas - es la ignorancia respecto a cuáles son las políticas e instituciones más eficientes para alcanzar el progreso. Así, hasta algunos años atrás se discutía con intensidad acerca de si la estrategia óptima de integración al comercio exterior era una de apertura amplia, o si ésta debía ser más selectiva, en el contexto de una estrategia de política industrial del tipo picking the winners. Si bien el debate no ha desaparecido, parece haber declinado —al menos a nivel técnico-, puesto que la experiencia ha sido contundente en destacar la importancia de una apertura significativa al exterior como vehículo para elevar la productividad agregada de la economía. En esta perspectiva, muchas de las recomendaciones en orden a promover una "apertura estratégica" se han desvanecido, en tanto —habitualmente- éstas no eran más que fórmulas conducentes a impedir o dilatar la apertura. 
La disponibilidad de información, junto con los efectos de la misma globalización en términos de competencia, redistribución de recursos y poder, son elementos que han contribuido a clarificar cuáles son las estrategias más eficaces para elevar el nivel de vida de la población de un país, como lo muestran las experiencias de Europa oriental, China e India, entre otros.

Lo que Thomas Friedman denomina -en su celebrado libro The World is Flat - el proceso de "aplanamiento" de la tierra es una fuerza que también genera nuevas instituciones y que, en alguna medida, permite la aparición del "tercer actor" que propugnaban AJR (2004). Ello en términos de parámetros e instituciones que reflejen otras instancias de evaluación de las políticas e instituciones domésticas. Pensemos, por ejemplo, en la importancia que han alcanzado los indicadores de riesgo país en el desarrollo de las decisiones de inversión, o en la aparición de mecanismos de solución de disputas como el $\mathrm{CIADI}^{22}$. En esta perspectiva, parece razonable suponer que una restricción a considerar en el desarrollo de propuestas conducentes, por ejemplo, a modificar el marco institucional del Banco Central, planteando para dicho organismo objetivos ajenos a lo que la mayoría de la profesión estima es su ámbito efectivo de influencia ${ }^{23}$, es el efecto que este tipo de iniciativas podría provocar sobre la percepción de riesgo país de los inversionistas, en un contexto donde la economía chilena registra una importante inserción a la economía mundial.

En la medida en que algunos países han acrecentado su inserción en la economía internacional, se ha producido un cierto ajuste en sus instituciones, de un modo acorde con el nuevo escenario. Así, el proceso de globalización ha promovido el desarrollo de nuevos esquemas de contratos y de solución de controversias, los que a menudo se encuentran fuera del ámbito de influencia de los países de origen de sus suscriptores. De este modo se ha producido una cierta tendencia a la globalización de algunos aspectos de las reglas de juego en las que se inserta la actividad. Un ejemplo de ello es lo que ha ocurrido con las economías pequeñas que se han incorporado a la Unión Europea, adoptando así esquemas institucionales que fueron impulsados por los países líderes de este proceso, Alemania y Francia.

Por el contrario, otros países — varios de ellos latinoamericanoshan evolucionado en la dirección contraria. Esto es, hacia una mayor autar-

${ }^{22}$ Centro Internacional de Arreglo de Diferencias Relativas a Inversiones, organismo vinculado al Banco Mundial.

${ }^{23}$ Como podría ser la promoción del crecimiento de la actividad y/o el empleo. 
quía, lo que ha contribuido a mantener esquemas institucionales poco amistosos con el desarrollo de la actividad productiva, obstruyendo así su inserción en la senda del crecimiento.

\section{La teoría institucional en el contexto del debate en torno al "Consenso de Washington"}

Como ha planteado Lucas (1996), la economía mundial continúa inmersa en la dinámica de innovación y crecimiento que se inició con la revolución industrial. Las economías que se han podido insertar de un modo más pleno y efectivo al comercio internacional han logrado alcanzar mejores niveles de vida. En la perspectiva de North y Acemoglu, se puede decir que estas economías han logrado dar forma a estructuras institucionales amistosas con la toma de riesgos productivos y la innovación.

De acuerdo con los desarrollos recientes en la literatura de crecimiento y desarrollo económico, la participación amplia de un país en el comercio internacional le acarrea numerosos beneficios, los que, como ha reconocido la literatura reciente, superan con creces los tradicionales beneficios ("triángulos") asociados a un mejor uso de los recursos disponibles $^{24}$. Dentro de los beneficios, adicionales a la reasignación, destaca el inherente a la adquisición de nuevos conocimientos por parte de la fuerza de trabajo, a través del proceso mismo de repetición que significa desarrollar una actividad productiva a una mayor escala, gracias al mayor tamaño de mercado que ofrece el mercado mundial. Esto es lo que en la literatura se identifica como el proceso de "aprendizaje en el trabajo" o de learning by doing.

Por otra parte, existe también la posibilidad de adquirir conocimientos como resultado de la interacción con economías más desarrolladas, que permitan ir cerrando — de acuerdo con el grado de integración al mundola "brecha de conocimiento". Éstos son los canales que identifica la literatura moderna para señalar la influencia de la apertura al exterior de una economía y su ritmo de crecimiento ${ }^{25}$.

Para Acemoglu y asociados, el nivel de subdesarrollo y estancamiento que registran numerosas economías de África y en menor grado las de Latinoamérica, debe ser analizado en una perspectiva más amplia que la inherente a una discusión relativa a ciertos aspectos del manejo económico, como sería el nivel de los aranceles aduaneros o el de las barreras no arancelarias. Para ellos, los disímiles resultados que se observan en términos de

\footnotetext{
${ }^{24} \mathrm{Al}$ respecto véase Romer (1994) y Kremmer (1993).

${ }^{25} \mathrm{Al}$ respecto véase Lucas (1993).
} 
desarrollo y dinamismo entre economías refleja —esencialmente- diferencias en la eficiencia del marco institucional vigente. De acuerdo con este enfoque, la forma e intensidad con la que una economía se relacione con el resto del mundo es uno de los aspectos a considerar; sin embargo, el análisis adecuado del problema exige revisar rigurosamente el conjunto de instituciones dentro de las cuales esta inserción internacional ocurre.

La relación entre reformas económicas —entendiendo por éstas una mezcla de acciones de política y cambios institucionales- y crecimiento económico ha adquirido cierta importancia en los últimos años, a raíz del cuestionamiento que han realizado algunos economistas a estrategias de política económica —denominadas como "ortodoxas” y que se identifican con el "Consenso de Washington"26 — que buscan impulsar el crecimiento a través de: acciones conducentes a elevar el grado de apertura de la economía; privatización de empresas públicas; desregulación, etc. Ello por cuanto plantean que la aplicación de dicha estrategia no resolvió los problemas de estancamiento de las economías que lo adoptaron y con frecuencia dichos episodios concluyeron con algún tipo de crisis macroeconómica. Para ilustrar este planteamiento, los economistas que han planteado este punto de vista — como Dani Rodrick - citan diversas experiencias de política económica en América Latina en las últimas décadas.

Más allá de la discusión misma de cada uno de los episodios que ellos consideran, el tema adquiere interés desde el punto de vista del presente trabajo, en la medida en que los mismos críticos de la agenda asociada al "Consenso de Washington” postulan que ésta adolece del defecto de no incorporar aspectos institucionales que hagan posible el éxito de las reformas propuestas. En efecto, para el propio Rodrick (2005) lo esencial en la suerte que corra un conjunto de reformas económicas son las características que tenga el marco institucional vigente. Así, en tanto éste sea favorable al desarrollo de la actividad productiva, es posible que diferentes sendas de política, en la dirección de hacer más eficiente la economía, concluyan siendo exitosas.

La interpretación que realizan Acemoglu y asociados acerca de la forma en que interactúan las diferentes variables que intervienen en el crecimiento provee una interesante alternativa de análisis para los aparentemente fallidos intentos por estimular el crecimiento a través de una combinación de políticas ortodoxas. Por ejemplo, en países como Argentina, Bolivia y Ecuador, entre otros.

${ }^{26} \mathrm{Al}$ respecto véase Rodrick (2005). 
Si bien cada uno de estos casos justificaría una investigación, dadas las particularidades que involucra un proceso de reformas económicas, a menudo no se requiere de un análisis demasiado exhaustivo para descubrir inconsistencias en la implementación de las mismas, las que podrían explicar su posterior fracaso. Al respecto no se debe perder de vista que la literatura empírica de crecimiento económico muestra que la relación entre políticas individuales y dicho proceso es relativamente débil, siendo lo relevante la adopción de "paquetes” coherentes de política ${ }^{27}$. En una perspectiva más amplia, resulta necesario establecer si el entorno institucional prevaleciente era coherente con el éxito de las reformas en ejecución, lo que nos devuelve al tema de las instituciones.

En términos generales, se plantea que el desempeño de una economía, caracterizado por un vector de variables estado $(x)$ que incluye la tasa de crecimiento del producto, es función de un conjunto de políticas que podemos asociar con $\phi$ y $\gamma$, las que se potencian mutuamente — de acuerdo con la idea de que lo relevante son los "paquetes de política”, los que reflejan una estrategia global más que políticas individuales-, y un índice de eficiencia global (A), el que se puede relacionar con el desarrollo institucional de esta economía, el que habría que asociar con determinados indicadores concretos.

$$
\text { (1) } x=\operatorname{AF}(\phi ; \gamma)=A \phi^{\alpha} \gamma^{\beta}
$$

Así, una combinación eficiente de políticas puede tener escaso impacto sobre el desempeño de la economía mientras no exista un marco institucional que contribuya a hacerlas efectivas. Pensemos por ejemplo en una política de liberalización de mercados y estímulos a la iniciativa privada, en un contexto en el que no existe el aparato jurídico para garantizar la propiedad y en el que prevalece la corrupción. Desde luego, la ausencia de los efectos esperados de la estrategia de política seguida no refleja un fracaso de ésta, sino que la presencia de un entorno inadecuado para lograr los beneficios que tal estrategia conlleva.

Para completar esta analogía con la teoría de la producción y el marco institucional, resulta evidente que la hipótesis que se plantea en la ecuación (1) es coherente con la teoría desarrollada por Acemoglu y asociados, en cuanto a que será el parámetro “A” el factor determinante del dinamismo de la economía en tanto se asuma que la productividad de las políticas individuales es decreciente en su dosis - lo que en general no parece absurdo- - y que la función de producción de la política económica tiene

\footnotetext{
${ }^{27} \mathrm{Al}$ respecto véase Levine y Renelt (1992).
} 
rendimientos constantes a la escala, lo que si bien puede ser un supuesto conveniente, parece más difícil de defender ${ }^{28}$.

Respecto al tema de la coherencia de las políticas, cabe mencionar — por ejemplo_ - las reformas impulsadas por Carlos Menem en Argentina con el propósito de estabilizar y luego dinamizar la economía. Por un lado, se utilizó la fijación del tipo de cambio al dólar ${ }^{29}$ como ingrediente esencial de la política de control de la inflación, pero no se lograron progresos importantes en el grado de flexibilidad del mercado laboral ni en la institucionalidad fiscal, siendo ambos elementos fundamentales para el éxito de un esquema cambiario como el mencionado. Por otra parte, la organización del gobierno - marco institucional- dificultó seriamente la gestión de las finanzas públicas en el caso argentino, puesto que cada provincia conservó un grado significativo de poder en este proceso, sin que existiesen normas efectivas para garantizar la búsqueda de equilibrios en las cuentas fiscales. Más aun, esta autonomía fiscal de las provincias en algún momento llevó a la creación de dineros locales, lo que evidentemente no era compatible con un cuadro de estabilidad macroeconómica en general y menos con la fijación del tipo de cambio.

Por otro lado, los sindicatos junto con otros poderes de facto, algunos vinculados a los partidos tradicionales ${ }^{30}$, conservaron un alto grado de influencia en la definición de las reglas del juego, lo que contribuyó a mantener un alto índice de corrupción en este país ${ }^{31}$, evidenciando así la existencia de una estructura institucional ineficiente y por lo tanto poco amistosa con el crecimiento.

Las privatizaciones de empresas públicas que se realizaron en este período fueron cuestionadas por falta de transparencia, lo que dificultó el logro de una aprobación pública al programa de reformas y apertura que ese gobierno se planteó.

Las debilidades del marco institucional dentro del cual se inserta la economía argentina se vieron acentuadas tras el default de la deuda externa, el uso de los fondos previsionales para el financiamiento del déficit fiscal y el incumplimiento de contratos de inversión extranjera en diferentes casos. Todos estos episodios representaron un quiebre drástico en la frágil institucionalidad vigente, causando un serio daño en la riqueza del sector privado

${ }^{28} \alpha+\beta=1$

${ }^{29}$ Esta política se identificó como "la ley de convertibilidad".

${ }^{30}$ Esencialmente al Partido Justicialista.

${ }^{31}$ En el Índice de Percepción de Corrupción que construye Transparencia Internacional, Argentina aparece ubicada en el año 2006 en un alto nivel internacional en términos de este problema, compartiendo su ubicación con países como Bolivia, Libia, Albania y Egipto. 
-incluyendo los inversionistas externos - y en la confianza en los anuncios de las autoridades correspondientes. En la experiencia de Argentina, desde la segunda mitad del siglo pasado se repiten con diferente intensidad episodios de expropiación masiva al sector privado, junto con una redefinición unilateral de contratos, lo que constituye un obstáculo importante para el éxito de cualquier programa de reformas dirigido a elevar la eficiencia de la economía.

Desde la perspectiva de la teoría institucional propuesta por North, Acemoglu y otros, se desprende que difícilmente Argentina podrá sostener altas tasas de crecimiento, más allá del período de recuperación que siguió a la crisis provocada por el quiebre en la regla cambiaria, en la medida en que no se configure un conjunto de reformas profundas y creíbles a la institucionalidad vigente, lo que implica reducir el peso político de facto que parecen mantener importantes sectores del país.

En el caso de Bolivia, el éxito de reformas económicas que promuevan una mayor apertura al exterior o una mayor participación del mercado en el proceso de asignación de recursos se ha enfrentado con una estructura institucional débil, junto con la predominancia de sectores —actualmente en el gobierno- que muestran una baja conexión cultural con los desarrollos de la sociedad moderna, los que propugnan fuertes reformas en la institucionalidad, pero en una dirección opuesta a la que prevalece en las economías que han logrado impulsar un proceso de crecimiento. A ello se añaden otras dificultades, como una alta percepción de corrupción, de acuerdo con el índice que elabora Transparencia Internacional.

En la búsqueda de una explicación para lo que denomina como el fracaso de la estrategia de política basada en el "Consenso de Washington”, Rodrick (2005) destaca la importancia de los factores institucionales en la determinación del éxito o fracaso de dichas reformas. Para Rodrick, un buen diseño institucional puede compensar las falencias de políticas más heterodoxas, así como su ausencia puede llevar al fracaso de estrategias inspiradas en los "principios económicos de primer orden". En esta categoría estarían algunas políticas de liberalización financiera y privatización de empresas públicas en América Latina durante la última década. Por el contrario, según Rodrick, las economías asiáticas fueron más cautelosas en el paso de las reformas, procurando que éstas fuesen aceptadas por la comunidad y coherentes con el diseño institucional vigente. Para ilustrar este punto señala el caso de la liberalización de precios en la agricultura china, la que se aplicó sobre ciertos excesos de producción respecto a las cuotas preestablecidas más que sobre el total de la producción. 
Si bien el planteamiento de Rodrick es debatible, por cuanto varios de los casos de reformas económicas que él asocia como dentro de la línea del "Consenso de Washington" no fueron coherentes con dicha estrategia, ello no impide reconocer que en esas reformas se observó - con frecuencia - un marco institucional poco amistoso con el desarrollo de la actividad productiva. Desde luego, queda pendiente la tarea empírica de establecer el peso relativo de ambos factores en el desempeño de las economías mencionadas, más allá de los factores cíclicos que pudieran repercutir en su desempeño de corto plazo.

En los casos someramente expuestos se encuentra evidencia favorable a la teoría institucional del crecimiento, en cuanto se descubre que más allá de la ejecución de un conjunto de reformas dirigidas a elevar la eficiencia global de la economía, en definitiva éstas no lograron su propósito debido a las debilidades y/o incoherencias que mostraba el marco institucional vigente. En alguna medida este diagnóstico se asocia con el requerimiento de simultaneidad de las reformas — en la forma de "paquetes" de políticas-, situación que en diversos casos no ocurrió en Latinoamérica, aunque apunta a algo más profundo y que se asocia con lo que Acemoglu y Johnson (2003) denominan como "property rights institutions" y “contracting institutions".

\section{El problema de causalidad}

La comprobación empírica de la "teoría institucional del crecimiento" es compleja. Por un lado, ésta requiere de la identificación y medición de indicadores que reflejen el desarrollo institucional de un país, lo que no es trivial, considerando que las definiciones habitualmente utilizadas para caracterizar dicho concepto subrayan aspectos diferentes. Así, por una parte se menciona la estabilidad en las reglas del juego como un rasgo esencial del desarrollo institucional, mientras que por otra se destacan las restricciones que enfrentan los gobernantes en el ejercicio de sus funciones. Se trata de dimensiones diferentes, las que eventualmente pueden llevar a interpretaciones contrapuestas respecto a cuál es el grado de desarrollo institucional de un país. Más aun, plasmar estos conceptos en algún indicador específico tampoco es sencillo y en la práctica éstos contienen un grado de arbitrariedad no despreciable.

En la práctica, es común encontrar estudios en los que el desarrollo institucional se evalúa en términos de un índice de riesgo de expropiación, índices de democracia o de respeto al marco legal vigente o imperio del 
derecho ${ }^{32}$. Cada uno de estos indicadores describe algún aspecto interesante relacionado con el marco institucional existente, aunque, como se indicó, enfocan cuestiones diferentes, lo que dificulta la evaluación del nexo entre instituciones y desempeño económico en un país.

Un segundo aspecto a considerar se refiere a la dirección de causalidad que se establece entre desarrollo institucional y crecimiento. De hecho podría plantearse que el crecimiento genera los recursos y la demanda por un fortalecimiento de las instituciones, lo que indica una causalidad opuesta a la que plantea la teoría institucional.

Para Glaeser, La Porta, López de Silanes y Shleifer (2004) el principal determinante del crecimiento es el capital humano, al tiempo que es esta misma variable la que impulsa el desarrollo institucional. Para ellos el nivel inicial de capital humano de una economía es un buen predictor de su posterior crecimiento, lo que no ocurre con el nivel inicial de las restricciones que enfrenta la autoridad de turno. Por otro lado, encuentran que no hay relación empírica entre la trayectoria del crecimiento de una economía y las variables que describen el marco constitucional vigente - como la independencia del poder judicial, la participación parlamentaria de diferentes sectores o la frecuencia de cambios constitucionales-, más que en indicadores de resultado, como las medidas del riesgo de expropiación. A su juicio, éste sería el test verdaderamente apropiado para la teoría institucional que impulsan Acemoglu y asociados.

Como se indicó anteriormente, un problema importante para el progreso de la investigación empírica en torno al vínculo entre instituciones y desempeño económico se refiere al establecimiento de una definición precisa para la idea de desarrollo institucional, junto con la elaboración de indicadores que la describan adecuadamente. Respecto a este punto, Glaeser et al. sostienen que la evaluación empírica de la teoría institucional adolecería de importantes limitaciones. Por ejemplo, señalan que el Índice de Riesgo de Expropiación — que utilizan AJR (2004) para evaluar el desarrollo institucional — no refleja adecuadamente dicha variable, puesto que a menudo un bajo nivel del mismo puede responder a la decisión estratégica de un gobernante que no enfrenta grandes restricciones políticas relevantes y que desea promover la economía de mercado - como ocurrió en varias experiencias exitosas de crecimiento del sudeste asiático-. Luego, un dictador que resuelve respetar los derechos de propiedad obtendrá un alto puntaje en desarrollo institucional, aunque ello sea incoherente con una perspectiva que asocia el progreso institucional con la solidez de una democracia.

${ }^{32}$ Rule of law. 
En el caso de China, por ejemplo, el dinamismo que esta economía registra en la última década se produce en un contexto que difícilmente podría ser calificado como de desarrollo institucional, considerando la precariedad existente en el sistema de protección a la propiedad privada. Para Glaeser et al., el factor determinante del impulso al crecimiento chino fue el enfoque pro crecimiento de la gestión de Deng, contrariamente a la visión estatista que antes impuso Mao, más que los cambios formales en la estructura institucional vigente. Para Glaeser et al. el stock de capital humano con que cuente un país es un determinante fundamental del desarrollo institucional. En su argumentación citan los planteamientos formulados por Lipset (1960), quien señala que en las sociedades más educadas es más probable el desarrollo de mecanismos pacíficos y eficientes de coordinación y resolución de conflictos.

En lo que se refiere a la "herencia institucional" de los conquistadores que analizan AJR, para Glaeser et al., lo que éstos trajeron a las colonias fue capital humano más que instituciones. Así, en la medida en que por diversas razones éstos decidieron asentarse en un lugar, su principal contribución al desarrollo del mismo fue el conjunto de conocimientos y habilidades que aportaron al proceso productivo, más que transformaciones institucionales. En esta perspectiva adquiere importancia el argumento de las externalidades que genera el conocimiento, como lo ha destacado la literatura moderna de teoría del crecimiento ${ }^{33}$.

Respecto a la relación entre capital humano-instituciones y crecimiento, Gallego (2006) sostiene que el desarrollo educacional de un país se explica — en buena medida - por las características institucionales dentro de las cuales se inserta este proceso. Así, plantea que la cantidad y la calidad del capital humano que se produjo en las colonias tuvo estrecha relación con el desarrollo democrático de éstas y con el grado de descentralización del poder político. De este modo, un mayor desarrollo democrático permitiría reaccionar de un modo más efectivo ante las demandas de la sociedad por una mejor educación, al tiempo que se elevaría la rentabilidad privada de ésta. Por otro lado, una mayor descentralización del poder político permitiría atender de un modo más directo y eficaz las necesidades educacionales de la comunidad. Luego, si se encuentra que las colonias que registraron un mejor desempeño fueron aquellas que contaban con un mejor y más abundante capital humano, para Gallego eso responde a un esquema institucional que alimentó dicho proceso de acumulación.

Para Glaeser et al., la interacción que se produce entre crecimiento, capital humano e instituciones se plantea de un modo diferente a lo indica-

${ }^{33} \mathrm{Al}$ respecto véase Lucas (2002). 
do por Acemoglu y asociados. El stock de capital humano y de capital social determinarán el conjunto de opciones posibles de organización institucional de una sociedad ${ }^{34}$. Mientras mayor sea la disponibilidad de dichas formas de capital, más amplias y atractivas serán las opciones institucionales. El conjunto de estos factores interactuará con el crecimiento, pero el determinante último del mismo sería — desde esta perspectiva - el capital humano. Luego, Glaeser et al. concluyen que “... la investigación sobre la economía de las instituciones, y en particular sobre los efectos de arreglos institucionales alternativos, debe centrarse en las reglas vigentes y no en evaluaciones conceptualmente ambiguas de sus resultados”35.

Un planteamiento similar al de Glaeser et al. realiza Barro (1999a), para quien el progreso institucional es el resultado del desarrollo económico. De hecho, para Barro es difícil que un país muy pobre pueda sostener un sistema democrático. Por otro lado, la implementación de una democracia que no cautele eficazmente el funcionamiento de las property rights institutions corre el riesgo de caer en la dinámica de las redistribuciones ineficientes desde el punto de vista del crecimiento, donde un numeroso grupo de personas pobres aumenta la carga tributaria de los pocos que pueden impulsar proyectos de inversión que ayuden a superar el bajo crecimiento y la pobreza.

En términos de la ecuación (1) antes expuesta, lo que este enfoque plantea es que el indicador de desarrollo institucional (A) sería creciente en el nivel de producto por habitante, de modo que una vez que se adoptan políticas que impulsan el crecimiento, se desarrolla una dinámica que conduce a un fortalecimiento del aparato institucional.

Una mirada alternativa de esta experiencia — aunque en buena medida coincidente con la de Glaeser et al.- corresponde a la planteada por Rodrick (2005), quien señala que el éxito chino consistió en no empujar las reformas más allá de las posibilidades que ofrecía el marco institucional existente. Esto es, se aplicaron políticas que impulsaron la inversión y la iniciativa privada, pero de un modo coherente con la realidad (restricción) que planteaba el marco institucional existente. A su juicio, si se hubiese pretendido avanzar más rápido en el proceso de reformas de lo que este marco podía acomodar, habríase creado una fuente de conflictos y tensiones sociales, lo que eventualmente habría llevado al fracaso de éstas.

Para Rodrick (2005), cualquier economía puede impulsar la tasa de crecimiento por un tiempo a través de la aplicación de reformas coherentes (2003).

${ }^{34}$ Esta idea fue planteada por Djankov, La Porta, López-de-Silanes y Shleifer

\footnotetext{
${ }^{35}$ Glaeser et al. (2004), p. 26.
} 
con la ortodoxia económica; sin embargo, sólo podrán sostener este ritmo de progreso aquellas economías que modifiquen sus esquemas institucionales de modo de hacer efectivas dichas reformas. Si bien este planteamiento es razonable y encuentra sustento en los desarrollos realizados por North, Acemoglu y otros, en el trabajo desarrollado por Rodrick queda pendiente un tratamiento más específico y concreto de esta hipótesis. En efecto, no se establecen cuáles aspectos de la institucionalidad vigente en aquellas economías que — a su juicio — adoptaron las "recomendaciones del Consenso de Washington” habrían conspirado contra las mismas. Esto es un aspecto esencial dentro del análisis de la eficacia de estrategias de desarrollo alternativas que plantea Rodrick.

Si el "grado de heterodoxia óptimo" es función de las restricciones que plantea al diseño de política económica el marco institucional, entonces la discusión debería darse en términos de cuáles son los aspectos específicos de este marco que intervienen en la definición de políticas alternativas, como también de la forma en que un determinado programa de reformas incorpora las reformas institucionales. Como se indicó antes, éste podría ser un camino promisorio de análisis, a la luz de lo observado, por ejemplo, con la experiencia chilena en materia de estabilidad económica e inflación, luego de la aplicación de profundas reformas en el marco en que se insertan el manejo de las finanzas públicas y la política monetaria.

\section{Discusión}

Las investigaciones lideradas por Daron Acemoglu respecto al vínculo entre instituciones y crecimiento han dado un renovado impulso a una agenda de investigación que tiene una larga tradición en economía. Una parte importante de estas investigaciones se ha dedicado a revisar la formación de las instituciones en el período colonial, como también el proceso que dio forma a la revolución industrial, episodio que también fue analizado por North anteriormente ${ }^{36}$. El "enfoque narrativo" que AJR (2004) utilizan para analizar esos episodios es atractivo; sin embargo, se necesita de una aplicación más extensa y sistemática de este marco analítico a otros episodios, ya sea que muestren un satisfactorio desempeño macroeconómico o lo contrario. Idealmente, sería deseable seguir la trayectoria de una economía cuyo desempeño ha sido cambiante a lo largo del tiempo.

Como se indicó anteriormente, para el desarrollo de un trabajo empírico sólido se requiere resolver primero aspectos complejos, como la identi-

${ }^{36}$ North (1981). 
ficación de aquellas variables que pueden caracterizar en mejor forma lo que se entiende por desarrollo institucional, lo que no es trivial.

En un plano más específico, la experiencia de países como Argentina y Chile a lo largo del siglo XX, el que inician con un fuerte dinamismo y una aventajada posición relativa dentro de la economía mundial, para posteriormente retroceder a un estado de relativo estancamiento e inestabilidad, sugiere la importancia de los cambios institucionales en dichos procesos, más que una eventual pérdida de capital humano o un deterioro tecnológico. En términos del Diagrama 1, planteado por AJR (2004), parece razonable suponer que la combinación de eventos exógenos a las políticas domésticas, como la Gran Depresión y la Segunda Guerra Mundial, causaron una redistribución del poder político en la sociedad, configurando un escenario propicio para la materialización de cambios institucionales, los que influyeron significativamente en la dinámica político-económica de las décadas siguientes. Desde luego, se requiere de una evaluación rigurosa de esta hipótesis para calificar las experiencias de Argentina y Chile en el Siglo XX como coherentes con la "teoría institucional del crecimiento".

En todo caso, en el análisis de episodios en los que existen signos de cambios en el grado de desarrollo institucional — ya sea en términos de mejoramiento o deterioro del mismo - es necesario advertir que AJR (2004) son cautos al señalar que subsisten importantes preguntas abiertas respecto a cómo y por qué se producen estos procesos ${ }^{37}$. Ciertamente éste es uno de los aspectos más atractivos que plantea la agenda de investigación en esta área.

Si bien la experiencia de países como Argentina y Chile puede servir de apoyo para esta teoría institucional, ello no parece ocurrir con los "tigres del sudeste asiático”, en los que no se aprecian cambios institucionales que pudiesen explicar su posterior crecimiento ${ }^{38}$. Más aun, si se considera el caso de economías que han registrado un fuerte crecimiento en la última década, como China e India, se puede apreciar en los Cuadros $\mathrm{N}^{\circ} 2$ y $\mathrm{N}^{\circ} 3$ que esas economías muestran un bajo desempeño en indicadores habitualmente utilizados para reflejar el desarrollo institucional, como son el Índice de Percepción de Corrupción y algunos indicadores de desarrollo institucional que se muestran en el Cuadro $\mathrm{N}^{\circ} 3$.

37 “...estamos muy lejos de contar con el marco analítico adecuado para reflexionar acerca de cómo se determinan las instituciones y por qué éstas varían de un país a otro. En otras palabras, aun cuando tenemos buenas razones para creer que las instituciones son importantes para el crecimiento económico, no disponemos aún de la estática comparativa básica que nos permitiría explicar por qué las instituciones económicas de equilibrio difieren”. AJR (2004), p. 2.

${ }^{38} \mathrm{Al}$ contrario de lo que ocurrió en Japón, donde sí se aprecian cambios institucionales importantes con anterioridad al fuerte crecimiento de la segunda mitad del siglo XX. 
CUADRO N 2: $\quad$ ÍNDICE DE PERCEPCIÓN DE CORRUPCIÓN*

\begin{tabular}{lcccccccc}
\hline & Finlandia & Argentina & Brasil & Chile & China & India & Singapur & EE.UU. \\
\hline & & & & & & & & \\
1998 & 9,6 & 3,0 & 4,0 & 6,80 & 3,5 & 2,9 & 9,1 & 7,5 \\
2001 & 9,9 & 3,5 & 4,0 & 7,50 & 3,5 & 2,7 & 9,2 & 7,6 \\
2005 & 9,6 & 2,8 & 3,7 & 7,30 & 3,2 & 2,9 & 9,4 & 7,6 \\
2007 & 9,4 & 2,9 & 3,5 & 7,00 & 3,5 & 3,5 & 9,3 & 7,2 \\
\hline
\end{tabular}

* El índice se mueve en el rango de 10-0. A mayor valor, más baja en la percepción de corrupción.

Fuente: www.transparency.org/policy.

CUADRO No 3: $\quad$ INDICADORES DE DESARROLLO INSTITUCIONAL 2005

\begin{tabular}{|c|c|c|c|c|c|c|c|c|c|}
\hline \multirow[b]{3}{*}{ Finlandia } & \multicolumn{3}{|c|}{ Imperio del derecho } & \multicolumn{3}{|c|}{ Control de la corrupción } & \multicolumn{3}{|c|}{ Estabilidad política } \\
\hline & 1996 & 2000 & 2006 & 1996 & 2000 & 2006 & 1996 & 2000 & 2006 \\
\hline & 1,92 & 1,89 & 1,95 & 2,29 & 2,34 & 2,57 & 1,19 & 1,48 & 1,47 \\
\hline Argentina & 0,12 & 0,13 & $-0,58$ & $-0,18$ & $-0,38$ & $-0,47$ & 0,11 & 0,05 & $-0,03$ \\
\hline Brasil & $-0,20$ & $-0,28$ & $-0,48$ & $-0,18$ & 0,09 & $-0,33$ & $-0,57$ & 0,11 & $-0,09$ \\
\hline Chile & 1,24 & 1,21 & 1,15 & 1,29 & 1,39 & 1,31 & 0,44 & 0,62 & 0,85 \\
\hline China & $-0,23$ & $-0,44$ & $-0,4$ & $-0,09$ & $-0,36$ & $-0,53$ & $-0,27$ & $-0,10$ & $-0,37$ \\
\hline India & 0,26 & 0,19 & 0,17 & $-0,36$ & $-0,33$ & $-0,21$ & $-1,12$ & $-0,66$ & $-0,84$ \\
\hline Singaspur & 1,75 & 1,43 & 1,82 & 2,25 & 2,25 & 2,3 & 1,07 & 1,15 & 1,3 \\
\hline EE.UU. & 1,74 & 1,66 & 1,57 & 1,75 & 1,77 & 1,3 & 0,94 & 1,14 & 0,31 \\
\hline
\end{tabular}

Fuente: Kaufmann, Kraay y Mastruzzi (2007).

En general, en los "tigres asiáticos" se encuentran economías que tenían un mercado laboral amplio y relativamente flexible, lo que permitió reflejar en los salarios una mano de obra competitiva en la economía mundial. Posteriormente el crecimiento se sostiene en una gran capacidad de aprovechamiento del tamaño de producción que permite el comercio internacional, lo que a juicio de economistas, como Lucas (1993), fue posible gracias a la capacidad de aprendizaje de la mano de obra doméstica. Así, de estas experiencias parece desprenderse un juicio más favorable a la hipótesis que subraya el papel del capital humano, tanto en el desarrollo institucional como en el crecimiento.

El análisis de la relación entre instituciones y desempeño económico ha tenido diversas manifestaciones en la literatura, el que ahora se traslada 
al tema del crecimiento. Cabe recordar la controversia que se planteó en los 90 acerca del grado de influencia del marco institucional en el que se inserta el manejo monetario en la tasa de inflación. Así, mientras algunos economistas destacaron la contribución de esquemas que limitan la discrecionalidad de las autoridades monetarias a través del otorgamiento de autonomía al banco central, otros — como Posen (1993) — cuestionaron dicho argumento, al postular que el énfasis antiinflacionario de la política monetaria depende más del peso político de los perdedores y los ganadores en este proceso, que de la institucionalidad en que se desenvuelve la autoridad monetaria. Esta hipótesis de Posen parece coherente con las fluctuaciones que ha experimentado la inflación en los Estados Unidos desde la segunda mitad del siglo pasado, en el contexto del mismo marco institucional.

Por otra parte, este cuestionamiento a la influencia de la institucionalidad en el desempeño económico de un país es implícitamente reconocido por Cukierman, Webb y Neyapti (1993), al distinguir entre autonomía efectiva y autonomía legal. De acuerdo con esta distinción, el análisis del verdadero impacto de las instituciones requiere hilar más fino en la elaboración de los índices de desarrollo institucional y en la identificación del peso relativo del poder político de facto con respecto al poder político de jure.

La literatura en general reconoce el carácter dinámico de la institucionalidad óptima. Así, lo que es adecuado en un cierto contexto deja de serlo en otro. Esto plantea la necesidad de revisar la dinámica de este proceso; por ejemplo, en función de los cambios que experimente el grado de integración al exterior de la economía. Éste es otro punto importante dentro de la agenda de investigación en el área, considerando los profundos cambios que han tenido lugar en la economía mundial en las últimas décadas y muy especialmente en el grado de integración de los países, como se indicó en la sección 5.

\section{Reflexiones finales sobre el caso chileno}

Como ya se señaló, el proceso de reformas económicas iniciado en Chile a partir de mediados de los 70 constituye una experiencia interesante de análisis respecto al vínculo entre instituciones y crecimiento.

Por un lado, se puede sostener que dicho proceso se produce luego de una severa crisis económica y política, en la cual tuvo una responsabilidad importante el marco institucional vigente. Por otra parte, un rasgo sobresaliente dentro del proceso de transformaciones que se inicia a mediados de los 70 es la configuración de un marco institucional más acorde con el desarrollo de la actividad productiva y con la estabilidad macroeconómica. 
Así, la combinación de: un sistema que promueve los acuerdos políticos y los gobiernos de mayoría; elevados quórum para modificar leyes de alto impacto (político o económico); la ley de Administración Financiera del Estado; la ley que establece la autonomía del Banco Central, y la protección constitucional a la propiedad privada, son factores que permiten explicar un profundo cambio en la economía chilena, el que posibilitó un importante progreso en los niveles de vida de la población. Todo lo anterior parece coherente con la visión de North y Acemoglu del crecimiento.

Como lo indica el propio Acemoglu, las instituciones —al definir los incentivos políticos y económicos - tienen adherentes y detractores, por lo que la dinámica que sigan depende del poder político relativo de cada grupo. Así, parece razonable sostener que las reformas económicas introducidas a partir de mediados de los 70 se vieron favorecidas por el evidente fracaso de lo que se entendía era el modelo alternativo. Esto redujo el poder de veto de aquellos grupos que en el pasado se habían visto favorecidos por las altas tarifas a las importaciones, la asignación selectiva del crédito y las regulaciones en general. De otro modo es difícil explicar cómo sectores con un importante peso político histórico, como la industria y la agricultura tradicional, no pudieron impedir un proceso sostenido de apertura de la economía chilena, a lo largo de más de treinta años ${ }^{39}$.

No obstante, si por diversas razones algunos grupos no pudieron contener la competencia y la apertura al exterior, otros sí lo han hecho, como por ejemplo los profesores, con el establecimiento del Estatuto Docente a comienzos de los 90, marco regulatorio que han logrado conservar, no obstante el amplio cuestionamiento técnico que se ha hecho a éste. En tanto se atribuya a la institucionalidad vigente en el sector educacional — esencialmente al Estatuto Docente- los deficientes resultados que muestra la educación en Chile, se apoyaría la tesis de Gallego, que coincidentemente con lo planteado por Acemoglu destaca la importancia de este factor en la determinación del stock y calidad del capital humano de una sociedad y no lo opuesto. En todo caso, ésta es otra manifestación del debate entre ambos enfoques expuesto anteriormente.

En alguna medida, en el mercado del trabajo se produce una situación parecida a la existente en el área educacional. Ello considerando la influencia que progresivamente han alcanzado cúpulas sindicales de relati-

${ }^{39}$ De acuerdo a lo señalado en diferentes análisis del proceso que llevó al gobierno militar a adoptar un modelo de economía de mercado, ésta no fue una opción clara desde un comienzo, en la medida en que al interior de las Fuerzas Armadas había un importante apoyo a la implementación de reformas menos radicales, que combinasen un cierto grado de mercado con un activo proceso de planificación. Al respecto véase, por ejemplo, Fontaine (1988). 
vamente baja representación, las que han logrado imponer sucesivas reformas que reducen el grado de flexibilidad en este mercado desde fines de los 90, cuando se intensificó la competencia política.

En ambos casos se replica, en algún grado, la lógica política prevaleciente hasta los 70, en tanto grupos de presión con una convocatoria relativamente pequeña lograron imponer su agenda en temas en los que, por su alto impacto agregado, habrían llevado a la reversión de la misma si pudiera imponerse la versión política del teorema de Coase.

El tema educacional y el laboral son especialmente importantes en la discusión de las perspectivas de crecimiento de la economía chilena, puesto que existe un alto grado de coincidencia a nivel técnico con respecto a la necesidad de llevar a cabo ajustes en la institucionalidad vigente en cada uno de los ámbitos mencionados, si se quiere recuperar una tasa de crecimiento más elevada. Sin embargo, los "perdedores" de las eventuales reformas a la institucionalidad vigente han sido efectivos en vetarlas, lo que evidentemente ha causado algún daño en el potencial de crecimiento de la economía.

En la medida en que el menor crecimiento origine una intensificación de las presiones por llevar a cabo redistribuciones que satisfagan las expectativas de progreso de los sectores de mayor peso político ${ }^{40}$, se podría ocasionar un daño severo a las perspectivas de crecimiento de mediano plazo.

\section{REFERENCIAS}

Acemoglu, Daron y Simon Johnson (2003): “Unbundling Institutions”. Working Paper 9934, NBER, agosto.

Acemoglu, Daron, Simon Johnson y James Robinson (AJR) (2004): "Institutions as the Fundamental Cause of Long-Run Growth”. Working Paper, 10481, NBER, mayo.

Barro, Robert J. y Xavier Sala-i-Martin (2004): Economic Growth. The MIT Press, segunda edición.

Barro, Robert J. (1996): "Democracy and Growth”. En Journal of Economic Growth, 1 (1): pp. 1-27.

(1997): "Determinants of Economic Growth: A Cross-Country Empirical Study”. Working Paper N ${ }^{\circ}$ 5698, NBER.

(1999a): "Determinants of Democracy”. En Journal of Political Economy, 107: 158-183.

- (1999b): "Determinants of Economic Growth: Implications of the Global Evidence for Chile”. En Cuadernos de Economía, Latin American Journal of Economics.

${ }^{40}$ En la lógica de “un juego de suma cero”. 
Bruhn, Miriam y Francisco Gallego (2006): “Good, Bad, and Ugly Colonial Activities: Studying Development Across the Americas”. Mimeo.

Cukierman, Alex, Sebastián Edwards y Guido Tabellini (1992): "Seignioriage and Political Instability”. En American Economic Review, junio.

Cukierman, Alex, L. Kalaitzidakis, L. Summers y S. Webb (1993): “Central Bank Independence, Growth, Investment and Real Rates”. En Carnagie-Rochester Conferences on Public Policy, 39: 95-140.

Cukierman, Alex, S. Webb y B. Neyapti (1993): "Measuring the Independence of Central Banks and Its Effect on Outcomes". En The World Bank Economic Review, Vol.6, $\mathrm{N}^{\circ}$ 3: 353-398.

Djankov, S., R. La Porta, F. Lopez-de-Silanes y A. Shleifer (2003): “The New Comparative Economics”. En Journal of Comparative Economics, 31 (4): 595-619.

Díaz, José, Rolf Lüders y Gert Wagner (2007): "La República en Cifras”. Documento de Trabajo, Instituto de Economía P. Universidad Católica de Chile.

Easterly, W. (1992): “How Much Does Policy Affect Growth?”. En Cuadernos de Economía, No 87 (agosto): 295-305.

Fontaine, Arturo (1988): Los Economistas y el Presidente Pinochet. Santiago: Editorial Zig Zag.

Fontaine, Juan Andrés (1989): "Banco Central: Autonomía para Cuidar la Estabilidad”. En Cuadernos de Economía, Año 26, No 77 (abril): 65-77, Pontificia Universidad Católica de Chile.

Gallego, F. A. (2006): "Historical Origins of Schooling: The Role of Political Decentralization”. En http://www.economia.puc.cl/archivos_profes/63/ historicalorigins.pdf

Glaeser, Edward L., Rafael La Porta, Florencio López-de-Silanes y Andrei Shleifer (2004): “Do Institutions Cause Growth?”. Working Paper No 10568, NBER, junio.

Greenspan, A. (2007): The Age of Turbulence: Adventures in a New World. The Penguin Press.

Hernández, L. y F. Parro (2008): “Economic Reforms, Financial Development and Growth: Lessons from the Chilean Experience”. En Cuadernos de Economía, No 131, Vol. 45 (mayo): 59-103.

Kaufmann, D., A. Kraay y M. Mastruzzi (2007): “Governance Matters VI: Agreggate and Individuals Indicators”. World Bank Working Policy Research Paper, № 4280.

Kremmer, M. (1993): “The O-Ring Theory of Economic Development”. En The Quaterly Journal of Economics (agosto): 551-557.

Larraín, F. y R. Vergara (2000): “Un Cuarto de Siglo de Reformas Fiscales”. En F. Larraín y R. Vergara (eds.), La Transformación Económica de Chile. Santiago: Centro de Estudios Públicos.

Leamer, Edward E. (2006): “A Flat World, a Level Playing Field, a Small World after all, or None of the Above?”. En Journal of Economic Literature (marzo).

Levine, R. y D. Renelt (1992): "A Sensitivity Analysis of Cross Country Growth Regressions”. En American Economic Review, Vol. 82, N 4: 942-963.

Lipset, S. M. (1960): Political Man: The Social Basis of Modern Politics. New York: Doubleday.

Lucas, Jr, Robert E. (1993): “Making a Miracle”. En Econometrica, Vol. 61, N²: 251272.

(1996): "La Revolución Industrial: Pasado y Futuro". En Estudios Públicos, $\mathrm{N}^{\circ} 64$ (primavera). 
(2002): Lectures on Economic Growth. Harvard University Press.

Maddison, Angus (2003): “ Estadísticas Actualizadas”. En www.ggdc.net/maddison/.

Méndez, J. C. (editor) (1979): Chilean Economic Policy. Santiago.

North, Douglass C. (1981): Structure and Change in Economic History. New York: Norton \& Co.

(1990): Institutions, Institutional Change, and Economic Performance. Cambridge: Cambridge University Press.

Posen, A. S. (1993): "Why Central Bank Independence Does Not Cause Low Inflation: There is No Institutional Fix for Politics". En O’Brien (ed.), Finance and the International Economy. Oxford University Press.

Rodrick, Dani (2005): “Growth Strategies”. En Philippe Aghion y Steven N. Durlauf (eds.), Handbook of Economic Growth, Vol. 1A. Elseveir.

Romer, Paul (1992): “Two Strategies for Economic Development: Using Ideas vs. Producing Ideas". En The World Bank Annual Conference on Economic Development. Washington D. C.: The World Bank.

(1994): "New Goods, Old Theory, and the Welfare Costs of Trade Restrictions". En Journal of Development Economics Vol. 43 (I), 5-38 (February).

Rosende, Francisco (2008): "La Conquista de la Inflación: Revisión y Análisis de la Literatura Reciente”. En Estudios Públicos N¹09 (verano).

(1989): "Elementos para el Diseño de un Marco de Análisis de la Autonomía del Banco Central”. En Cuadernos de Economía, año 26, № 77 (abril): 25-38.

Palabras clave: instituciones; crecimiento económico.

Clasificación. JEL: O43, D72.

Recibido: enero de 2008; aceptado: agosto de 2008. 